Article

\title{
High-Resolution $\alpha$-Glucosidase Inhibition Profiling Combined with HPLC-HRMS-SPE-NMR for Identification of Antidiabetic Compounds in Eremanthus crotonoides (Asteraceae)
}

\author{
Eder Lana e Silva ${ }^{1}$, Jonathas Felipe Revoredo Lobo ${ }^{1}$, Joachim Møllesøe Vinther ${ }^{2}$, \\ Ricardo Moreira Borges ${ }^{1}$ and Dan Staerk ${ }^{2, *}$ \\ 1 Instituto de Pesquisas de Produtos Naturais, Centro de Ciências da Saúde, \\ Universidade Federal do Rio de Janeiro, Rio de Janeiro 21941-902, Brazil; eder_lls@hotmail.com (E.L.S.); \\ jonnyuff@gmail.com (J.F.R.L.); ricardo_mborges@yahoo.com.br (R.M.B.) \\ 2 Department of Drug Design and Pharmacology, Faculty of Health and Medical Sciences, \\ University of Copenhagen, Universitetsparken 2, Copenhagen DK-2100, Denmark; jomq@elektro.dtu.dk \\ * Correspondence: ds@sund.ku.dk; Tel.: +45-35336177
}

Academic Editor: Isabel C. F. R. Ferreira

Received: 9 May 2016; Accepted: 8 June 2016; Published: 16 June 2016

\begin{abstract}
Glucosidase inhibitors decrease the cleavage- and absorption rate of monosaccharides from complex dietary carbohydrates, and represent therefore an important class of drugs for management of type 2 diabetes. In this study, a defatted ethyl acetate extract of Eremanthus crotonoides leaves with an inhibitory concentration ( $\left.\mathrm{IC}_{50}\right)$ of $34.5 \mu \mathrm{g} / \mathrm{mL}$ towards $\alpha$-glucosidase was investigated by high-resolution $\alpha$-glucosidase inhibition profiling combined with HPLC-HRMS-SPE-NMR. This led to identification of six $\alpha$-glucosidase inhibitors, namely quercetin (16), trans-tiliroside (17), luteolin (19), quercetin-3-methyl ether (20), 3,5-di-O-caffeoylquinic acid $n$-butyl ester (26) and 4,5-di-O-caffeoylquinic acid $n$-butyl ester (29). In addition, nineteen other metabolites were identified. The most active compounds were the two regioisomeric di-O-caffeoylquinic acid derivatives $\mathbf{2 6}$ and 29 , with $\mathrm{IC}_{50}$ values of 5.93 and $5.20 \mu \mathrm{M}$, respectively. This is the first report of the $\alpha$-glucosidase inhibitory activity of compounds $\mathbf{2 0}, \mathbf{2 6}$, and $\mathbf{2 9}$, and the findings support the important role of Eremanthus species as novel sources of new drugs and/or herbal remedies for treatment of type 2 diabetes.
\end{abstract}

Keywords: diabetes; HPLC-HRMS-SPE-NMR; $\alpha$-glucosidase; Eremanthus crotonoides

\section{Introduction}

Type 2 diabetes (T2D) is a chronic metabolic disorder that constitutes a global health problem, being responsible for almost $90 \%$ of all cases of diabetes in adults [1]. In 2014, approximately 348 million people suffered from T2D worldwide, and this number is estimated to reach 439 million in 2030 [2,3]. Severe micro- and macrovascular complications in T2D are caused by postprandial hyperglycemia following $\alpha$-glucosidase-catalyzed hydrolysis of dietary carbohydrates-but the hydrolysis and absorption of glucose can be reduced by $\alpha$-glucosidase inhibitors [4,5]. Acarbose, voglibose and miglitol are currently accepted clinical drugs for treatment of TD2. However, several side effects have been reported [6,7], which makes the search for new $\alpha$-glucosidase inhibitors of utmost importance. From this perspective, the very recent development of state-of-the-art high-resolution bioassays combined with hyphenation of high-performance liquid chromatography, high-resolution mass spectrometry, solid-phase extraction and nuclear magnetic resonance spectroscopy [8], i.e., HR-bioassay/HPLC-HRMS-SPE-NMR has been an important tool for identification of $\alpha$-glucosidase 
inhibitors from plant and food extracts [9-14]-including the development of dual and triple high-resolution inhibition profiling [15-17]. Furthermore, the HR-bioassay/HPLC-HRMS-SPE-NMR platform has successfully been applied for identification of $\alpha$-amylase inhibitors [18], fungal plasma membrane $\mathrm{H}^{+}$-ATPase inhibitors [19], antioxidants [20] and monoamine oxidase A inhibitors [21].

In our ongoing search for antidiabetic compounds from natural sources, Eremanthus crotonoides (DC.) Sch. Bip. (Asteraceae) was included in our screening of extracts for $\alpha$-glucosidase inhibitory activity. Asteraceae is one of the most important plant families concerning natural products-based treatment of diabetes [22]. The genus Eremanthus Less. comprises 27 species geographically restricted to the Brazillian Cerrado, but there are some exceptions, like E. crotonoides that can also be found in the Restinga [23]. Previous phytochemical analysis of the genus led to identification of flavonoids, quinic acid derivatives, terpenes and sesquiterpene lactones [23-28]. Despite the importance of Asteraceae as plant-based remedies for management of diabetes, there are no reports on investigations of the antidiabetic activity of Eremanthus species. Thus, in this study, we used high-resolution $\alpha$-glucosidase inhibition profiling in combination with HPLC-HRMS-SPE-NMR for investigation of $\alpha$-glucosidase inhibitors in E. crotonoides.

\section{Results and Discussion}

\subsection{High-Resolution $\alpha$-Glucosidase Inhibition Profiling of Extract}

In our on-going screening programme for antidiabetic compounds from plants and foods, a defatted ethyl acetate extract of E. crotonoides showed an inhibitory concentration ( $\mathrm{IC}_{50}$ ) of $34.5 \mu \mathrm{g} / \mathrm{mL}$ towards $\alpha$-glucosidase, and was therefore selected for further investigation. Thus, $0.4 \mathrm{mg}$ of the extract of E. crotonoides was subjected to analytical-scale reversed-phase HPLC, and the eluate in the retention time range from 3.0 to $78.0 \mathrm{~min}$ was fractionated into four 96-well microplates, yielding a resolution of 4.7 data points/min (the first column of each microplate was reserved for blanks and controls). This was followed by evaporation of the HPLC eluate from all wells, reconstitution in buffer containing $10 \%$ DMSO, and assessment of the $\alpha$-glucosidase inhibitory activity of all wells (final concentration of DMSO during assay $=5 \%$ ). The inhibitory activities (calculated as percentage inhibition) were plotted against the retention time from the microfractionation to give the high-resolution $\alpha$-glucosidase inhibition profile (biochromatogram) shown in Figure 1. The HPLC chromatogram at $254 \mathrm{~nm}$ is shown with the blue line (top) and the high-resolution $\alpha$-glucosidase inhibition profile shown with the red line at the bottom. The high resolution of the biochromatogram allows direct correlation of HPLC peaks and peaks in the biochromatogram - thereby pinpointing peaks corresponding to compounds with $\alpha$-glucosidase inhibitory activity.

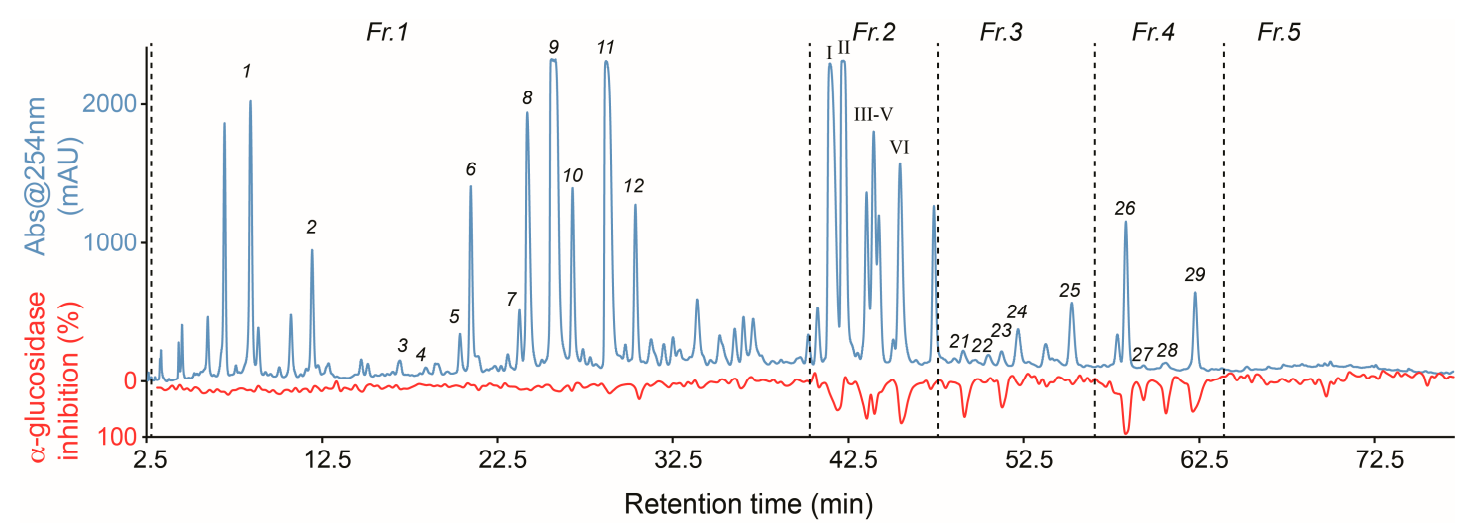

Figure 1. High-resolution $\alpha$-glucosidase inhibition profile (red line) of defatted ethyl acetate extract of E. crotonoides shown underneath the HPLC chromatogram (blue line) at $254 \mathrm{~nm}$. Fr.1-Fr.5 indicates the five regions collected by preparative-scale HPLC on $\mathrm{C}_{18}$ column for subsequent HPLC-HRMS-SPE-NMR analysis using analytical-scale pentafluorophenyl column 
The chromatogram shows several peaks in the range 5-65 min, with satisfactory separation of all major peaks, except in the range from 40 to $48 \mathrm{~min}$. There seems to be minor $\alpha$-glucosidase inhibitory activity correlated with peaks 11 and 12, but otherwise the majority of peaks correlated with strong $\alpha$-glucosidase inhibitory activity are observed from 40 to $65 \mathrm{~min}$. For dereplication purposes, the defatted extract was subjected to HPLC-HRMS-SPE-NMR analysis. This led to direct structural identification of 5-O-caffeoylquinic acid (1) [10], caffeic acid (2) [29], quercetin 3-O- $\beta$-D-glucoside (6) [10], 3-O-caffeoylquinic acid ethyl ester (7) [30], 3,4-di-O-caffeoylquinic acid (8) [31], 3,5-di-O-caffeoylquinic acid (9) [31], isorhamnetin-3-O- $\beta$-D-glucoside (10) [32], 4,5-di-O-caffeoylquinic acid (11) [10], quercetin-3-O-(6"-(E)-O-caffeoyl)- $\beta$-D-glucoside (12) [33], apigenin (22) [10], kaempferol (24) [34], centratherin (25) [35], 3,5-di-O-caffeoylquinic acid $n$-butyl ester (26) [36] and 4,5-di-O-caffeoylquinic acid $n$-butyl ester (29) [36] (Figure 2) directly from the extract, based on comparison of HRMS and NMR data obtained in the HPLC-HRMS-SPE-NMR mode (Table S1 in Supplementary Materials) with data from literature.

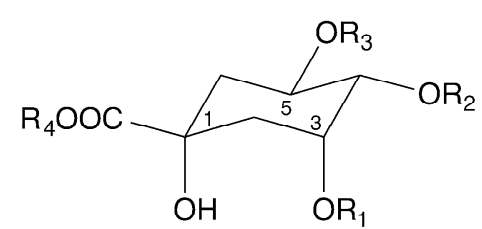

1: $R_{1}=R_{2}=R_{4}=H, R_{3}=$ caffeoyl

3: $R_{1}=R_{2}=H, R_{3}=$ caffeoyl, $R_{4}=\mathrm{CH}_{3}$

7: $R_{1}=$ caffeoyl, $R_{2}=R_{3}=H, R_{4}=C_{2} C_{2} C_{3}$

8: $R_{1}=R_{2}=$ caffeoyl, $R_{3}=R_{4}=H$

9: $R_{1}=R_{3}=$ caffeoyl, $R_{2}=R_{4}=H$

11: $R_{2}=R_{3}=$ caffeoyl, $R_{1}=R_{4}=H$

13: $R_{1}=R_{3}=$ caffeoyl, $R_{2}=H, R_{4}=C_{2} C_{2}$

14: $R_{1}=H, R_{2}=R_{3}=$ caffeoyl, $R_{4}=C_{2} C_{3}$

26: $R_{1}=R_{3}=$ caffeoyl, $R_{2}=H, R_{4}=\mathrm{CH}_{2} \mathrm{CH}_{2} \mathrm{CH}_{2} \mathrm{CH}_{3}$

29: $\mathrm{R}_{1}=\mathrm{H}, \mathrm{R}_{2}=\mathrm{R}_{3}=$ caffeoyl, $\mathrm{R}_{4}=\mathrm{CH}_{2} \mathrm{CH}_{2} \mathrm{CH}_{2} \mathrm{CH}_{3}$<smiles>CC(C)C(=O)/C=C/c1ccc(O)c(O)c1</smiles><smiles>[R]c1cc(C=CC(=O)O)ccc1O</smiles><smiles>OCC1=CC(O)[C@H](O)[C@H](O)C1</smiles>

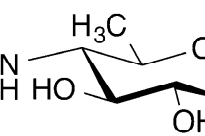<smiles>[R2]c1c(-c2ccc(O)c(Br)c2)oc2cc(O)cc(O)c2c1=O</smiles>

5: $\mathrm{R}_{1}=\mathrm{OH}, \mathrm{R}_{2}=\beta-\mathrm{D}-\mathrm{Gal}$

6: $\mathrm{R}_{1}=\mathrm{OH}, \mathrm{R}_{2}=\beta$-D-Glc

10: $R_{1}=O_{C H}, R_{2}=\beta$-D-Glc

12: $\mathrm{R}_{1}=\mathrm{OH}, \mathrm{R}_{2}=\left(6^{\prime \prime}-\mathrm{O}-(E)\right.$-caffeoyl)- $\beta$-D-Glc

15: $R_{1}=H, R_{2}=\left(6^{\prime \prime}-O-(Z)-p\right.$-coumaroyl) $-\beta-D-G \mid c$

16: $\mathrm{R}_{1}=\mathrm{R}_{2}=\mathrm{OH}$

17: $\mathrm{R}_{1}=\mathrm{H}, \mathrm{R}_{2}=(6 "-O-(E)-p$-coumaroyl) $-\beta$-D-Glc

18: $\mathrm{R}_{1}=\mathrm{OCH}_{3}, \mathrm{R}_{2}=\left(6^{\prime \prime}-O-(E)-p\right.$-coumaroyl) $-\beta$-D-Glc

19: $\mathrm{R}_{1}=\mathrm{OH}, \mathrm{R}_{2}=\mathrm{H}$

20: $\mathrm{R}_{1}=\mathrm{OH}, \mathrm{R}_{2}=\mathrm{OCH}_{3}$

22: $\mathrm{R}_{1}=\mathrm{R}_{2}=\mathrm{H}$

24: $\mathrm{R}_{1}=\mathrm{H}, \mathrm{R}_{2}=\mathrm{OH}$

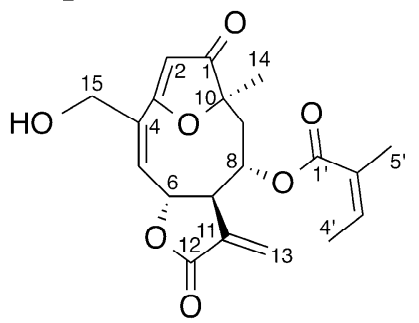

25

Figure 2. Acarbose and compounds identified in Eremanthus crotonoides.

\subsection{Identification of Inhibitory Constituents}

The material eluted with the two major peaks I and II (Figure 1) in the retention time range 40-43 min were correlated with $44 \% \alpha$-glucosidase inhibition. The material eluted with the next three intense but overlapping peaks III-V displayed $52 \%$ to $62 \% \alpha$-glucosidase inhibition, whereas the 
material eluted with peak VI showed $69 \% \alpha$-glucosidase inhibition. Despite several attempts, it was not possible to develop an analytical-scale HPLC method for base-line separation of peaks I-V directly from the crude defatted extract. Thus, to investigate the material eluted with these peaks and some of the other minor peaks, the crude defatted extract of E. crotonoides was subject to preparative-scale reversed-phase HPLC to collect five major fractions (Fr.1-Fr.5 indicated in Figure 1).

Fraction Fr.1 was subjected to HPLC-HRMS-SPE-NMR analysis using an optimized separation method, which allowed identification of minor peaks $3-5$ as 5-O-caffeoylquinic acid methyl ester (3) [29], $p$-coumaric acid (4) [37], quercetin 3-O- $\beta$-D-galactoside (5) [38] based on comparison of HRMS and NMR data obtained in the HPLC-HRMS-SPE-NMR mode (Table S1 in Supplementary Materials) with data from literature. Furthermore, a higher amount of 6, $\mathbf{1 0}$ and $\mathbf{1 2}$ allowed acquisition of high-quality heteronuclear multiple bond correlation (HMBC) experiments which could not be directly obtained using the crude defatted extract.

Fraction Fr.2 was submitted to analytical-scale pentafluorophenyl (PFP) HPLC microfractionation, and an $\alpha$-glucosidase biochomatogram was constructed for identification of $\alpha$-glucosidase inhibitors. Figure 3 shows the chromatogram at $254 \mathrm{~nm}$ (blue line) and the high-resolution $\alpha$-glucosidase inhibition profile obtained from microfractionation of Fr.2 (red line).

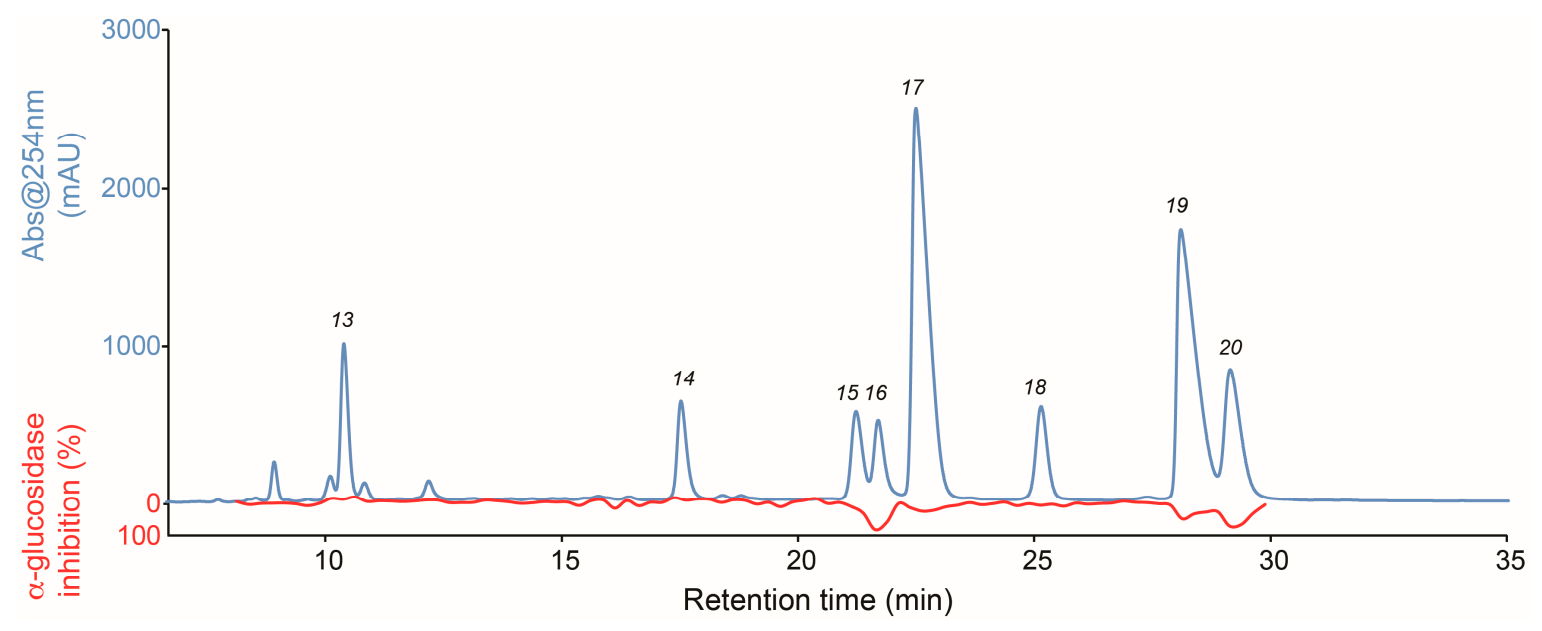

Figure 3. High-resolution $\alpha$-glucosidase inhibition profile of fraction Fr.2 (red) shown underneath the HPLC chromatogram at $254 \mathrm{~nm}$ (blue).

The biochromatogram shows that peaks 16, 17, 19, and 20 are correlated with $\alpha$-glucosidase inhibitory activity of $82 \%, 23 \%, 32 \%$, and $70 \%$, respectively. For identification of the bioactive compounds, fraction Fr.2 was subjected to HPLC-HRMS-SPE-NMR analysis with trapping of peaks 13-20 after separation of ten successive injections; thereby ensuring high-quality NMR data for the trapped peaks. Based on HRMS as well as 1D and 2D NMR data (Table S1 in Supplementary Materials) obtained in the HPLC-HRMS-SPE-NMR mode, the peaks were identified as 3,5-di-O-caffeoylquinic acid ethyl ester (13) [39], 4,5-di-O-caffeoylquinic acid ethyl ester (14) [31], cis-tiliroside (15) [40], quercetin (16) [13], trans-tiliroside (17) [40], isorhamnetin-3-O-(6"-O-(E)-p-coumaroyl)- $\beta$-D-glucoside (18) [41], luteolin (19) [10] and quercetin 3-methyl ether (20) [34]. Peaks 15 and 18 were trapped in a separate HPLC-HRMS-SPE-NMR experiment with higher injection volumes in order to acquire HMBC data with sufficient high signal intensity (example of ${ }^{1} \mathrm{H}$ and heteronuclear HSQC and HMBC for compound 15 are given in Supplementary Materials Figure S1a-c).

The identity of minor active peaks 21, 23, 27, and 28 could not be established from HPLC-HRMS-SPE-NMR analysis of the extract, vide supra, because the trapped fractions were impure and the analytes they contained were present in too low amounts. Despite several efforts, their identities could also not be established by HPLC-HRMS-SPE-NMR analysis after optimized separation of fractions Fr.3 and Fr.4. 


\subsection{Isolation and Pharmacological Evaluation of the $\alpha$-Glucosidase Inhibitors}

This is the first investigation of antidiabetic activity of an Eremanthus species, and it led to identification of six $\alpha$-glucosidase inhibitors by high-resolution $\alpha$-glucosidase inhibition profiling combined with HPLC-HRMS-SPE-NMR, i.e., four flavonoids (16, 17, 19, and 20) and two di-O-caffeoylquinic acid derivatives (26 and 29). Compounds 20, 26 and 29 are known compounds, but their $\alpha$-glucosidase inhibitory activity $(70 \%, 92 \%$, and $57 \%$, respectively, as direct readouts from the biochromatogram) is reported for the first time. However, the percent inhibition in the biochromatogram are only relative inhibitions, since no information about the quantity of the individual constituents are available from these experiments. Thus, in order to isolate the $\alpha$-glucosidase inhibitors for $\mathrm{IC}_{50}$ determination, fractions Fr.2 and Fr.4 were submitted to repeated analytical-scale HPLC fractionation using a PFP column. The flavonoids quercetin (16), trans-tiliroside (17), luteolin (19) and quercetin-3-methyl ether (20) were isolated from fraction Fr.2, whereas the di-O-caffeoylquinic acids derivatives 3,5-di- $O$-caffeoylquinic acid $n$-butyl ester (26) and 4,5-di-O-caffeoylquinic acid $n$-butyl ester (29) were isolated from fraction Fr.4.

The isolated compounds and acarbose (reference compound) were tested for their inhibitory activity of yeast $\alpha$-glucosidase, and IC $_{50}$ curves for acarbose, 26 and 29 are shown in Figure 4 and $\mathrm{IC}_{50}$-values for all tested compounds are given in Table 1.
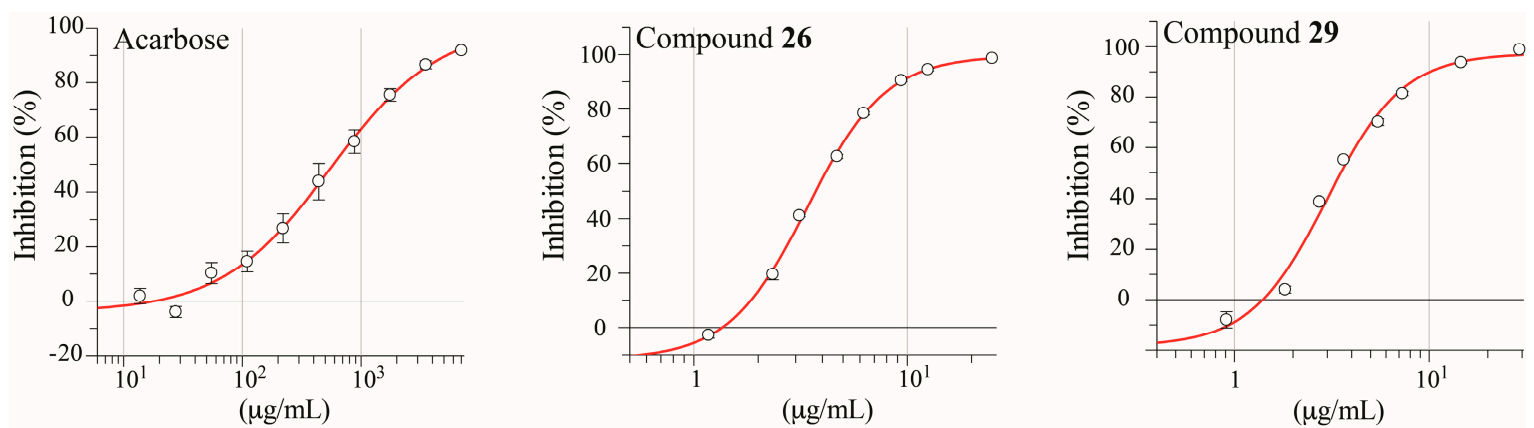

Figure 4. $\mathrm{IC}_{50}$ curves of Acarbose, 26 and 29.

Table 1. Inhibitory activities of the bioactive compounds and reference compound acarbose.

\begin{tabular}{cc}
\hline Sample & $\mathbf{I C}_{\mathbf{5 0}}(\boldsymbol{\mu M})^{\mathbf{a}}$ \\
\hline Acarbose & $859.79 \pm 0.09$ \\
$\mathbf{1 6}$ & $7.19 \pm 0.06$ \\
$\mathbf{1 7}$ & $\mathrm{ND}^{\mathrm{c}, \mathrm{d}}$ \\
$\mathbf{1 9}$ & $59.64 \pm 1.32$ \\
$\mathbf{2 0}$ & $20.36 \pm 1.30$ \\
$\mathbf{2 6}$ & $5.93 \pm 0.12$ \\
$\mathbf{2 9}$ & $5.20 \pm 0.30$
\end{tabular}

a Values represent means \pm SD deviation of triplicate experiments; ${ }^{b}$ Reference compound; ${ }^{\mathrm{c}} \mathrm{IC}_{50}$ value not reached at concentration of $210 \mu \mathrm{M} ;{ }^{\mathrm{d}}$ Inhibition at $210 \mu \mathrm{M}=4.5 \%$.

Compounds 16, 17, and 19 have all previously been reported as $\alpha$-glucosidase inhibitors [42,43], but this is the first report of the $\alpha$-glucosidase inhibitory activity of 20, 26, and 29. Compounds 16, 19, 20, 26, and 29 all showed higher $\alpha$-glucosidase inhibitory activity than the clinically approved antidiabetic drug acarbose (Table 1), which supports the use of Eremanthus as an antidiabetic herbal medicine.

Flavonoids are well-recognized $\alpha$-glucosidase inhibitors, and in this work we report the $\alpha$-glucosidase inhibitory activity of yet another flavonoid, quercetin-3-methyl ether (20). This compound has previously been reported as an inhibitor of human aldose reductase, another key therapeutic target in T2D [44]. Quercetin (16) showed higher $\alpha$-glucosidase inhibitory activity than the 
new inhibitor 20 and luteolin (19), suggesting that methoxylation and hydroxylation at C-3 increase the inhibitory activity against yeast $\alpha$-glucosidase. trans-Tiliroside (17) was less effective than flavonoids 16, 19 and 20. Previous reports have described that flavonoid glycosides show lower $\alpha$-glucosidase inhibitiory activity than free aglycones $[9,10]$.

The regioisomers 3,5-di-O-caffeoylquinic acid $n$-butyl ester (26) and 4,5-di-O-caffeoylquinic acid $n$-butyl ester (29) showed the highest inhibitory effects in the $\alpha$-glucosidase assay. The use of plants that contain these metabolites for the treatment of T2D has been reported in folk medicine [36,45-47]. However, to the best of our knowledge, this is the first report regarding antidiabetic properties of compounds 26 and 29. The similar non-esterified di-O-caffeoylquinic acids (compounds 8, 9 and 11) showed no or very low $\alpha$-glucosidase inhibitiory activity as seen in the biochromatogram of E. crotonoides extract. Compound $\mathbf{1 1}$ is known as a weak inhibitor $\left(\mathrm{IC}_{50}>100 \mu \mathrm{M}\right)$ [31], which indicates that the $n$-butyl esterification in di-O-caffeoylquinic acid derivatives enhances the inhibitory activity against $\alpha$-glucosidase.

\section{Materials and Methods}

\subsection{Reagents}

HPLC grade methanol and acetonitrile, petroleum ether, $\mathrm{CDCl}_{3}$, methanol- $d_{4}$, dimethyl sulfoxide, acarbose, $p$-nitrophenol $\alpha$-D-glucopyranoside (PNPG) and $\alpha$-glucosidase type I (EC 3.2.20, from Saccharomyces cerevisiae, lyophilized powder) were purchased from Sigma-Aldrich (St. Louis, MO, USA). Methanol and ethyl acetate used for extraction were purchased from Tedia (Fairfield, OH, USA). Formic acid was obtained from Merck (Darmstadt, Germany) and water was prepared by a deionization and 0.22- $\mu \mathrm{m}$ membrane filtration system (Milipore, Billerica, MA, USA).

\subsection{Plant Material and Sample Preparation}

Leaves of E. crotonoides were collected in Restinga-Jurubatiba National Park, Rio de Janeiro, Brazil and identified by botanist Dr. Marcelo Guerra Santos. A voucher specimen has been deposited at the Herbarium of the Faculdade de Formaçãode Professores, Universidade Estadual do Rio de Janeiro, Brazil (M. Guerra Santos 2150). A portion (100 g) of the air-dried and powdered leaves was extracted with ethyl acetate $(3 \times 800 \mathrm{~mL})$ using $24 \mathrm{~min}$ ultrasonication at room temperature, and the extract was subsequently dried under reduced pressure. The crude extract ( $4.0 \mathrm{~g}$ ) was dissolved in $\mathrm{H}_{2} \mathrm{O}: \mathrm{MeOH}$ (2:8) and defatted with petroleum ether. The defatted ethyl acetate extract was dissolved in methanol and filtered using Nylon Target Syringe Filters $(0.45 \mu \mathrm{m}$ pore size Thermo Scientific, Waltham, MA, USA) for further HPLC analysis.

\subsection{High-Resolution $\alpha$-Glucosidase Biochromatogram}

Microfractionation was performed with an Agilent 1200 series instrument (Santa Clara, CA, USA) consisting of a G1316A quartenary pump, a G1322A degasser, a G1316A thermostatted column compartment, a G1315C photodiode-array detector, a G1364C fraction collector, and a G1367C high-performance auto sampler, controlled by Agilent ChemStation ver. B.03.02 software. The columns used were a Phenomenex $\mathrm{C}_{18}(2)$ Luna $(150 \mathrm{~mm} \times 4.6 \mathrm{~mm}, 3 \mu \mathrm{m}$ particle size, $100 \AA$ pore size) and a Phenomenex PFP Kinetex $(150 \mathrm{~mm} \times 4.6 \mathrm{~mm}, 2.6 \mu \mathrm{m}$ particle size, $100 \AA$ pore size $)$. For fractionation of the crude defatted ethyl acetate extract of E. crotonoides (injection: $4 \mu \mathrm{L}$; concentration: $100 \mathrm{mg} / \mathrm{mL}$ ) the temperature was maintained at $40{ }^{\circ} \mathrm{C}$ and the flow rate at $0.5 \mathrm{~mL} / \mathrm{min}$. The solvents were a binary gradient mixture of water-acetonitrile $(95: 5 v / v)$ as eluent $\mathrm{A}$ and acetonitrile-water $(95: 5 v / v)$ as eluent $\mathrm{B}$, both acidified with $0.1 \%$ formic acid. The following elution profile was used: $0 \mathrm{~min}, 10 \% \mathrm{~B} ; 35 \mathrm{~min}$, $26 \% \mathrm{~B} ; 50 \mathrm{~min}, 35 \% \mathrm{~B} ; 60 \mathrm{~min}, 40 \% \mathrm{~B} ; 90 \mathrm{~min}, 100 \% \mathrm{~B}$, and the eluate from 3 to $78 \mathrm{~min}$ was fractionated into four 96-well microplates, leading to a resolution of 4.7 data points per min. For fractionation of Fr.2 (injection: $2 \mu \mathrm{L}$; concentration: $33 \mathrm{mg} / \mathrm{mL}$ ) the same conditions as described above were used, but with methanol and the PFP column instead of acetonitrile and the $C_{18}$ column. The eluate from 8 to 
30 min was fractionated into one 96-well microplate (resolution: 4.0 data points per min) using the following gradient: $0 \mathrm{~min}, 50 \% \mathrm{~B} ; 3 \mathrm{~min}, 50 \% \mathrm{~B} ; 34 \mathrm{~min}, 59 \% \mathrm{~B} ; 35 \mathrm{~min} \mathrm{100 \%} \mathrm{B;} 38 \mathrm{~min}, 100 \% \mathrm{~B}$. The collected fractions were evaporated to dryness using a Savant SPD121P speed vacuum concentrator coupled with a RVT400 refrigerated vapor trap and an OFP-400 oil free pump (Holbrook, NY, USA). The $\alpha$-glucosidase inhibitiory activity of the fractions was determined according to the previously described procedure [9]. Briefly, the content of each well was dissolved in $100 \mu \mathrm{L}$ of $0.1 \mathrm{M}$ phosphate buffer containing $10 \%$ of DMSO and added $80 \mu \mathrm{L}$ of the $\alpha$-glucosidase solution. After incubation at $28{ }^{\circ} \mathrm{C}$ for $10 \mathrm{~min}$ the reaction was initiated by addition of $20 \mu \mathrm{L}$ of PNPG (10 mM in phosphate buffer) (final volume $=200 \mu \mathrm{L}$ and final DMSO $=5 \%$ ). The cleavage product of PNPG was monitored at $405 \mathrm{~nm}$ for $35 \mathrm{~min}$ using a Multiskan FC microplate photometer (Thermo Scientific, Waltham, MA, USA) and the percentage enzyme inhibition was calculated. The $\alpha$-glucosidase inhibition of each well was plotted at their respective retention times underneath the HPLC chromatogram to obtain a high-resolution biochromatogram.

\subsection{HPLC-HRMS-SPE-NMR Analysis}

HPLC-HRMS-SPE-NMR analyses of crude defatted ethyl acetate extract and fractions of E. crotonoides were performed using an Agilent 1260 series chromatographic HPLC system consisting of a G1311B quaternary pump with built-in degasser, a G1329B autosampler, a G1316A thermostatted column compartment, and a G1315D photodiode-array detector. The crude defatted extract of E. crotonoides was separated using the same conditions (mobile phases, column, flow rate and elution gradient) as described above. Fraction Fr. 2 was subjected to HPLC-HRMS-SPE-NMR analysis (injection: $2 \mu \mathrm{L}$; concentration of fraction Fr.2: $28 \mathrm{mg} / \mathrm{mL}$ ) using the same conditions above, but with the following gradient $0 \mathrm{~min}, 50 \% \mathrm{~B} ; 5 \mathrm{~min}, 50 \% \mathrm{~B} ; 35 \mathrm{~min}, 63 \% \mathrm{~B} ; 36 \mathrm{~min}, 100 \% \mathrm{~B} ; 40 \mathrm{~min}, 100 \%$ B. Peaks 15 and 18 were trapped in a separate HPLC separation with a higher injection volume and concentration of fraction Fr.2 (injection: $7 \mu \mathrm{L}$; concentration of fraction Fr.2: $58 \mathrm{mg} / \mathrm{mL}$ ) using the same conditions as described above for this fraction, but with the following gradient method: $0 \mathrm{~min}, 50 \% \mathrm{~B} ; 30 \mathrm{~min}$, $63 \% \mathrm{~B} ; 31 \mathrm{~min}$ 100\% B; $35 \mathrm{~min}, 100 \%$ B. Fraction Fr. 1 (injection: $8 \mu \mathrm{L}$; concentration of fraction Fr.1: $88 \mathrm{mg} / \mathrm{mL}$ ) was analyzed with the same conditions as the extract of E. crotonoides, but with the following gradient method: $0 \mathrm{~min}, 10 \% \mathrm{~B} ; 35 \mathrm{~min}, 24 \% \mathrm{~B} ; 37 \mathrm{~min}, 100 \% \mathrm{~B} ; 45 \mathrm{~min}, 100 \% \mathrm{~B}$. For all separations, approximately $1 \%$ of the HPLC eluate was directed to a micrOTOF-Q II mass spectrometer (Bruker Daltonik $\mathrm{GmbH}$, Bremen, Germany) equipped with an electrospray ionization (ESI) interface. Mass spectra were acquired in negative ion mode, using a drying temperature of $200{ }^{\circ} \mathrm{C}$, capillary voltage of $4100 \mathrm{~V}$, nebulizer pressure of 2.0 bar and a dry gas flow of $7 \mathrm{~L} / \mathrm{min}$. The other approximately $99 \%$ of the HPLC eluate was directed to the PDA detector and subsequently diluted with $1 \mathrm{~mL} / \mathrm{min}$ of water by means of a Knauer Smartline Pump 100 (Knauer, Berlin, Germany), to a prospect 2 SPE-unit (Spark Holland, Emmen, The Netherlands). Before trapping, the cartridges were preconditioned with $500 \mu \mathrm{L}$ of acetonitrile and subsequently equilibrated with $500 \mu \mathrm{L}$ of water. Cumulative SPE trappings of the selected peaks on SPE cartridges (Hysphere GP phase, $10 \times 2 \mathrm{~mm}$ i.d., from Spark Holland, Emmen, The Netherlands) were performed for 10 repeated separations for all HPLC analyses described above using absorption thresholds ( 254 and $320 \mathrm{~nm}$ ) for trapping. Subsequently, the cartridges were dried with pressurized nitrogen gas for $45 \mathrm{~min}$ each and eluted into 1.7-mm o.d. NMR tubes (Bruker Biospin, Karlsruhe, Germany) with methanol-d $d_{4}$ (final volume in tube $30 \mu \mathrm{L}$ ) using a Gilson 215 liquid handler (Gilson, Middleton, WI, USA) controlled by Prep Gilson software Version 1.2 (Bruker Biospin). MS measurements, HPLC separations and analyte trapping on SPE cartridges were controlled using Hystar version 1.2 software (Bruker Daltonik).

\subsection{NMR Experiments}

All NMR spectra were recorded in methanol- $d_{4}$ at $300 \mathrm{~K}$ and ${ }^{1} \mathrm{H}$ and ${ }^{13} \mathrm{C}$ chemical shifts were referenced to the residual solvent signal ( $\delta 3.31$ and $\delta 49.00$, respectively) (compound 25 was also analyzed in $\left.\mathrm{CDCl}_{3}\right)$. The experiments were performed with a Bruker Avance III system $\left({ }^{1} \mathrm{H}\right.$ operating 
frequency of $600.13 \mathrm{MHz}$ ) equipped with a Bruker Samplejet autosampler and a cryogenically cooled gradient inverse triple-resonance $1.7 \mathrm{~mm}$ TCI probe-head (Bruker Biospin) optimized for ${ }^{1} \mathrm{H}$ and ${ }^{13} \mathrm{C}$ observation. Bruker standard pulse sequences were used throughout this study. Icon NMR (version 4.2, Bruker Biospin) was used for controlling automated acquisition of NMR data (temperature equilibration to $300 \mathrm{~K}$, optimization lock parameters, gradient shimming, and setting of receiver gain). NMR data processing was performed using topspin (version 3.1, Bruker Biospin). One-dimensional ${ }^{1} \mathrm{H}$-NMR spectra were acquired with $30^{\circ}$-pulses, $3.66 \mathrm{~s}$ inter-pulse intervals, $64 \mathrm{k}$ data points and multiplied with an exponential function corresponding to line-broadening of $0.3 \mathrm{~Hz}$ prior to Fourier transform. Phase-sensitive DQF-COSY and NOESY spectra were recorded using a gradient-based pulse sequence with a $20 \mathrm{ppm}$ spectral width and $2 \mathrm{k} \times 512$ data points (processed with forward linear prediction to $1 \mathrm{k}$ data points). Multiplicity-edited HSQC spectra were acquired with the following parameters: spectral width $20 \mathrm{ppm}$ for ${ }^{1} \mathrm{H}$ and $200 \mathrm{ppm}$ for ${ }^{13} \mathrm{C}, 2 \mathrm{k} \times 256$ data points (processed with forward linear prediction to $1 \mathrm{k}$ data points), and $1.0 \mathrm{~s}$ relaxation delay. HMBC spectra were optimized for ${ }^{\mathrm{n}} J_{\mathrm{C}, \mathrm{H}}=8 \mathrm{~Hz}$ and acquired using the following parameters: spectral width $20 \mathrm{ppm}$ for ${ }^{1} \mathrm{H}$ and $240 \mathrm{ppm}$ for ${ }^{13} \mathrm{C}, 2 \mathrm{k} \times 128$ data points (processed with forward linear prediction to $1 \mathrm{k}$ data points), and $1.0 \mathrm{~s}$ relaxation delay

\subsection{Isolation and Evaluation of the Bioactive Compounds}

The crude defatted ethyl acetate extract of E. crotonoides was subjected to reversed-phase preparative-scale HPLC fractionation (six injections of $900 \mu \mathrm{L}$; concentration: $100 \mathrm{mg} / \mathrm{mL}$; flow: $20 \mathrm{~mL} / \mathrm{min}$ ) to collect five major fractions: Fr.1 (157 mg), Fr.2 (128 mg), Fr.3 (39 mg), Fr.4 (44 mg), and Fr.5 (78 mg). Preparative-scale fractionation was performed using an Agilent 1100 series instrument equipped with a multiple wavelength detector, an autosampler and two preparative-scale solvent delivery pumps. The column used was a Phenomenex $\mathrm{C}_{18}$ (2) Luna $(250 \mathrm{~mm} \times 21.2 \mathrm{~mm}, 5 \mu \mathrm{m}$ particle size, $100 \AA$ A pore size) and the gradient method was as follows: $0 \mathrm{~min}, 20 \% \mathrm{~B} ; 27 \mathrm{~min}, 35 \% \mathrm{~B} ; 37 \mathrm{~min}$, $40 \% \mathrm{~B} ; 40 \mathrm{~min}, 100 \% \mathrm{~B} ; 46 \mathrm{~min}, 100 \% \mathrm{~B} ; 47 \mathrm{~min}, 20 \% \mathrm{~B} ; 52 \mathrm{~min}, 20 \% \mathrm{~B}$ using a binary mixture of water-acetonitrile $(95: 5 v / v)$ as eluent $A$ and acetonitrile-water $(95: 5 v / v)$ as eluent $B$, both acidified with $0.1 \%$ formic acid. Fraction Fr.2 was subjected to PFP analytical-scale fractionation (40 injections of $3 \mu \mathrm{L}$ each; concentration of fraction Fr.2: $78 \mathrm{mg} / \mathrm{mL}$; collection threshold: $1050 \mathrm{mAU}$ at $254 \mathrm{~nm}$; column temperature: $40^{\circ} \mathrm{C}$; flow: $0.5 \mathrm{~mL} / \mathrm{min}$ ) using the same system of solvents as described above (but with methanol instead of acetonitrile) and the following gradient: $0 \mathrm{~min}, 50 \% \mathrm{~B} ; 5 \mathrm{~min}, 50 \% \mathrm{~B} ; 30 \mathrm{~min}$, $58 \% \mathrm{~B} ; 31 \mathrm{~min}, 100 \% \mathrm{~B} ; 35 \mathrm{~min}, 100 \% \mathrm{~B} ; 36 \mathrm{~min}, 50 \% \mathrm{~B} ; 40 \mathrm{~min}, 50 \% \mathrm{~B}$ to yield compounds 16 ( $0.5 \mathrm{mg})$, 17 (1.3 mg), 19 (1.1 mg) and 20 (0.8 mg). Fraction Fr.4 was subjected to PFP HPLC analytical-scale purification (20 injections of $6 \mu \mathrm{L}$ each; concentration of fraction Fr.4: $66 \mathrm{mg} / \mathrm{mL}$; collection threshold: $450 \mathrm{mAU}$ at $254 \mathrm{~nm}$ ) using the same conditions as described for Fr.2 and the following gradient: $0 \mathrm{~min}$, $55 \%$ B; $5 \mathrm{~min}, 55 \%$ B; $20 \mathrm{~min}, 75 \%$ B; $21 \mathrm{~min}, 100 \%$ B; $26 \mathrm{~min}, 100 \%$ B; $27 \mathrm{~min}, 55 \%$ B; $32 \mathrm{~min}, 55 \%$ B to yield compounds $\mathbf{2 6}(1.2 \mathrm{mg}$ ) and $\mathbf{2 9}(1.4 \mathrm{mg})$. The system used for fractionation of fractions Fr.2 and Fr.4 was the same as described in Section 3.3. The purity of the isolated compounds was assessed by ${ }^{1} \mathrm{H}-\mathrm{NMR}$ spectroscopy, and dilution series of the isolated compounds and acarbose (reference) were assessed for $\alpha$-glucosidase inhibitory activity. The inhibition of the tested compounds was calculated using Equation (1).

$$
\% \text { Inhibition }=\{(\text { slope control }- \text { slope sample }) / \text { slope control })\} \times 100
$$

These values were used for dose-response curves, and $\mathrm{IC}_{50}$ values were determined using GraFit (version 5.0.11) from Erithacus Software.

\section{Conclusions}

The present study demonstrated that Eremanthus species can be used as a natural source of $\alpha$-glucosidase inhibitors. The HR-bioassay/HPLC-HRMS-SPE-NMR platform led to fast identification 
of three known compounds with already reported $\alpha$-glucosidase inhibitory activity as well as three known compounds for which the $\alpha$-glucosidase inhibitory activity is reported for the first time. Furthermore, use of the HPLC-HRMS-SPE-NMR platform led to identification of nineteen additional molecules. The results showed that the $n$-butyl group plays an important role for the strong $\alpha$-glucosidase inhibitory activity of compounds $\mathbf{2 6}$ and 29 towards yeast $\alpha$-glucosidase. These compounds are potential candidates for development of novel antidiabetic drugs and should be investigated in more detailed in vitro and in vivo studies.

Supplementary Materials: Supplementary materials can be accessed at: http://www.mdpi.com/1420-3049/ 21/6/782/s1.

Acknowledgments: This work had financial support from CAPES (Coordenação de Aperfeiçoamento de Pessoal de Nível Superior) under the protocol number 99999.000416/2015-00. HPLC equipment used for high-resolution bioassay was obtained via a grant from The Carlsberg Foundation. The $600 \mathrm{MHz}$ HPLC-HRMS-SPE-NMR system used in this work was acquired through a grant from "Apotekerfonden af 1991", The Carlsberg Foundation, and the Danish Agency for Science, Technology and Innovation via the National Research Infrastructure funds.

Author Contributions: E.L.S., J.F.R.L., J.M.V., R.M.B. and D.S. participated in the design of the study, data analysis and preparation of the manuscript. E.L.S. performed the majority of the experimental work, and E.L.S. and D.S. took the lead in the first draft of the manuscript

Conflicts of Interest: The authors declare no conflict of interest.

\section{References}

1. Scully, T. Diabetes in numbers. Nature 2012, 485, S2-S3. [CrossRef] [PubMed]

2. Flores-Bocanegra, L.; Pérez-Vásquez, A.; Torres-Piedra, M.; Bye, R.; Linares, E.; Mata, R. $\alpha$-Glucosidase inhibitors from Vauquelinia corymbosa. Molecules 2015, 20, 15330-15342. [CrossRef] [PubMed]

3. Zhang, P.; Zhang, X.; Brown, J.; Vistisen, D.; Sicree, R.; Shaw, J. Global healthcare expenditure on diabetes for 2010 and 2030. Diabetes Res. Clin. Pract. 2010, 87, 293-301. [CrossRef] [PubMed]

4. Sheng, Z.; Dai, H.; Pan, S.; Wang, H.; Hu, Y.; Ma, W. Isolation and characterization of an $\alpha$-Glucosidase inhibitor from Musa spp. (Baxijiao) flowers. Molecules 2014, 19, 10563-10573. [CrossRef] [PubMed]

5. Ceriello, A. Postprandial hyperglycemia and diabetes complications: Is it time to treat? Diabetes 2005, 54, 1-7. [CrossRef] [PubMed]

6. Fujisawa, T.; Ikegami, H.; Inoue, K.; Kawabata, Y.; Ogihara, T. Effect of two $\alpha$-glucosidase inhibitors, voglibose and acarbose, on postprandial hyperglycemia correlates with subjective abdominal symptoms. Metabolism 2005, 54, 387-390. [CrossRef] [PubMed]

7. Krentz, A.J.; Bailey, C.J. Oral antidiabetic agents: Current role in type 2 diabetes mellitus. Drugs 2005, 65, 385-411. [CrossRef] [PubMed]

8. Lambert, M.; Stærk, D.; Hansen, S.H.; Jaroszewski, J.W. HPLC-SPE-NMR hyphenation in natural products research: Optimization of analysis of Croton membranaceus extract. Magn. Reson. Chem. 2005, 43, 771-775. [CrossRef] [PubMed]

9. Schmidt, J.S.; Lauridsen, M.B.; Dragsted, L.O.; Nielsen, J.; Staerk, D. Development of a bioassay-coupled HPLC-SPE- $t$ NMR platform for identification of $\alpha$-glucosidase inhibitors in apple peel (Malus $\times$ domestica borkh.). Food Chem. 2012, 135, 1692-1699. [CrossRef] [PubMed]

10. Wubshet, S.G.; Schmidt, J.S.; Wiese, S.; Staerk, D. High-resolution screening combined with HPLC-HRMS-SPE-NMR for identification of potential health-promoting constituents in sea aster and searocket-New Nordic food ingredients. J. Agric. Food Chem. 2013, 61, 8616-8623. [CrossRef] [PubMed]

11. Schmidt, J.S.; Nyberg, N.T.; Staerk, D. Assessment of constituents in Allium by multivariate data analysis, high-resolution $\alpha$-glucosidase inhibition assay and HPLC-SPE-NMR. Food Chem. 2014, 161, 192-198. [CrossRef] [PubMed]

12. Kongstad, K.T.; Özdemir, C.; Barzak, A.; Wubshet, S.G.; Staerk, D. Combined use of high-resolution $\alpha$-glucosidase inhibition profiling and HPLC-HRMS-SPE-NMR for investigation of antidiabetic principles in crude plant extracts. J. Agric. Food Chem. 2015, 63, 2257-2263. [CrossRef] [PubMed]

13. Wubshet, S.G.; Moresco, H.H.; Tahtah, Y.; Brighente, I.M.C.; Staerk, D. High-resolution bioactivity profiling combined with HPLC-HRMS-SPE-NMR: $\alpha$-Glucosidase inhibitors and acetylated ellagic acid rhamnosides from Myrcia palustris DC. (Myrtaceae). Phytochemistry 2015, 116, 246-252. [CrossRef] [PubMed] 
14. Liu, B.; Kongstad, K.T.; Wiese, S.; Jäger, A.K.; Staerk, D. Edible seaweed as future functional food: Identification of $\alpha$-glucosidase inhibitors by combined use of high-resolution $\alpha$-glucosidase inhibition profiling and HPLC-HRMS-SPE-NMR. Food Chem. 2016, 203, 16-22. [CrossRef] [PubMed]

15. Liu, B.; Kongstad, K.T.; Qinglei, S.; Nyberg, N.T.; Jäger, A.K.; Staerk, D. Dual high-resolution $\alpha$-glucosidase and radical scavenging profiling combined with HPLC-HRMS-SPE-NMR for identification of minor and major constituents directly from the crude extract of Pueraria lobata. J. Nat. Prod. 2015, 78, 294-300. [CrossRef] [PubMed]

16. Tahtah, Y.; Kongstad, K.T.; Wubshet, S.G.; Nyberg, N.T.; Jønsson, L.H.; Jäger, A.K.; Qinglei, S.; Staerk, D. Triple aldose reductase / $\alpha$-glucosidase/radical scavenging high-resolution profiling combined with high-performance liquid chromatography-High-resolution mass spectrometry-solid-phase extraction-nuclear magnetic resonance spectroscopy for identification of antidiabetic constituents in crude extract of Radix Scutellariae. J. Chromatogr. A 2015, 1408, 125-132. [PubMed]

17. Wubshet, S.G.; Tahtah, Y.; Heskes, A.M.; Kongstad, K.T.; Pateraki, I.; Hamberger, B.; Møller, B.M.; Staerk, D. Identification of PTP1B and $\alpha$-glucosidase inhibitory serrulatanes from Eremophila spp. by combined use of dual high-resolution PTP1B and $\alpha$-glucosidase inhibition profiling and HPLC-HRMS-SPE-NMR. J. Nat. Prod. 2016. in press.

18. Okutan, L.; Kongstad, K.T.; Jäger, A.K.; Staerk, D. High-resolution $\alpha$-amylase assay combined with high-performance liquid chromatography-solid-phase extraction-nuclear magnetic resonance spectroscopy for expedited identification of $\alpha$-amylase inhibitors: Proof of concept and $\alpha$-amylase inhibitor in cinnamon. J. Agric. Food Chem. 2014, 62, 11465-11471. [CrossRef] [PubMed]

19. Kongstad, K.T.; Wubshet, S.G.; Johannesen, A.; Kjellerup, L.; Winther, A.-M.L.; Jäger, A.K.; Staerk, D. High-resolution screening combined with HPLC-HRMS-SPE-NMR for identification of fungal plasma membrane $\mathrm{H}^{+}$-ATPase inhibitors from plants. J. Agric. Food Chem. 2014, 62, 5595-5602. [CrossRef] [PubMed]

20. Wiese, S.; Wubshet, S.G.; Nielsen, J.; Staerk, D. Coupling HPLC-SPE-NMR with a microplate-based high-resolution antioxidant assay for efficient analysis of antioxidants in food-Validation and proof-of-concept study with caper buds. Food Chem. 2013, 141, 4010-4018. [CrossRef] [PubMed]

21. Grosso, C.; Jäger, A.K.; Staerk, D. Coupling of a high-resolution monoamine oxidase-A inhibitor assay and HPLC-SPE-NMR for advanced bioactivity-profiling of plant extracts. Phytochem. Anal. 2013, 24, 141-147. [CrossRef] [PubMed]

22. Sidhy, M.C.; Sharma, T. A database of antidiabetic plant species of Family Asteraceae, Euphorbiaceae, Fabaceae, Lamiaceae and Moraceae. Int. J. Herbal Med. 2013, 2, 187-199, 2321-2187.

23. Lobo, J.F.R.; Castro, E.S.; Gouvea, D.R.; Fernandes, C.P.; Almeida, F.B.; Amorim, L.M.F.; Burth, P.; Rocha, L.; Santos, M.G.; Harmerski, L.; et al. Antiproliferative activity of Eremanthus crotonoides extracts and centratherin demonstrated in brain tumor cell lines. Rev. Bras. Farmacogn. 2012, 22, 1295-1300. [CrossRef]

24. Bohlmann, F.; Zdero, C.; King, R.M.; Robinson, H. Sesquiterpene lactones from Eremanthus species. Phytochemistry 1980, 19, 2663-2668. [CrossRef]

25. Vichnewski, W.; Takahashi, A.M.; Nasi, A.M.T.; Rodrigues, D.C.; Gonçalves, G.; Dias, D.A.; Lopes, J.N.C.; Goedken, V.L.; Gutiérrez, A.B.; Herz, W. Sesquiterpene lactones and other constituents from Eremanthus seidelii, E. goyazensis and Vanillosmopsis erythropappa. Phytochemistry 1989, 28, 1441-1151. [CrossRef]

26. Gouvea, D.R.; Gobbo-Neto, L.; Sakamoto, H.T.; Lopes, N.P.; Lopes, J.L.C.; Meloni, F.; Amaral, J.G. Seasonal variation of the major secondary metabolites present in the extract of Eremanthus mattogrossensis Less (Asteracea: Vernonieae) leaves. Quim. Nova 2012, 35, 2139-2145. [CrossRef]

27. Silvério, M.S.; Del-Vechio-Vieira, G.; Pinto, M.A.O.; Alves, M.S.; Souza, O.V. Chemical composition and biological activities of essential oils of Eremanthus erythropappus (DC) McLeisch (Asteraceae). Molecules 2013, 18, 9785-9796. [CrossRef] [PubMed]

28. Bohlmann, F.; Singh, P.; Zdero, C.; Ruhe, A.; King, R.M.; Robinson, H. Furanoheliangolides from two Eremanthus species and from Chresta sphaerocephala. Phytochemistry 1982, 21, 1669-1673. [CrossRef]

29. Lee, E.J.; Kim, J.S.; Kim, H.P.; Lee, J.H.; Kang, S.S. Phenolic constituents from the flower buds of Lonicera japonica and their 5-lipoxygenase inhibitory activities. Food Chem. 2010, 120, 134-139. [CrossRef]

30. Fuchs, C.; Spiteller, G. Rapid and easy identification of isomers of coumaroyl- and caffeoyl-D-quinic acid by gas chromatography mass spectrometry. J. Mass. Spectrom. 1996, 31, 602-608. [CrossRef] 
31. Chen, J.; Mangelinckx, S.; Ma, L.; Wang, Z.; Li, W.; de Kimpe, N. Caffeoylquinic acid derivatives isolated from the aerial parts of Gynura divaricata and their yeast alpha-glucosidase and PTP1B inhibitory activity. Fitoterapia 2014, 99, 1-6. [CrossRef] [PubMed]

32. Kong, C.S.; Kim, J.A.; Qian, Z.J.; Kim, Y.A.; Lee, J.I.; Kim, S.K.; Nam, T.J.; Seo, Y. Protective effect of isorhamnetin 3-O- $\beta$-D-glucopyranoside from Salicornia herbacea against oxidation-induced cell damage. Food Chem. Toxicol. 2009, 47, 1914-1920. [CrossRef] [PubMed]

33. Calzada, F.; Cedillo-Rivera, R.; Mata, R. Antiprotozoal activity of the constituents of Conyza filaginoides. J. Nat. Prod. 2001, 64, 671-673. [CrossRef] [PubMed]

34. Rashed, K.; Sahuc, M.E.; Deloison, G.; Calland, N.; Brodin, P.; Rouille, Y.; Seron, K. Potent antiviral activity of Solanum rantonnetii and the isolated compounds against hepatitis C virus in vitro. J. Funct. Foods 2014, 11, 185-191. [CrossRef]

35. Soares, A.C.F.; Silva, A.N.; Matos, P.M.; da Silva, E.H.; Heleno, V.C.G.; Lopes, N.P.; Lopes, J.L.C.; Sass, D.C. Complete ${ }^{1} \mathrm{H}$ and ${ }^{13} \mathrm{C}$ NMR structural assignments for a group of four goyazensolide-type furanoheliangolides. Quim. Nova 2012, 35, 2205-2207. [CrossRef]

36. Wei, X.Y.; Huang, H.J.; Wu, P.; Cao, H.L.; Ye, W.H. Phenolic constituents from Mikania micrantha. Biochem. Syst. Ecol. 2004, 32, 1091-1096. [CrossRef]

37. Yi, B.; Hu, L.; Mei, W.; Zhou, K.; Wang, H.; Luo, Y.; Wei, X.; Dai, H. Antioxidant phenolic compounds of cassava (Manihot esculenta) from Hainan. Molecules 2011, 16, 10157-10167. [CrossRef] [PubMed]

38. Lee, D.Y.; Shrestha, S.; Seo, W.D.; Lee, M.H.; Jeong, T.S.; Cho, J.H.; Song, Y.C.; Kang, H.W.; Rho, Y.D.; Baek, N.I. Structural and quantitative analysis of antioxidant and low-density lipoprotein-antioxidant flavonoids from the grains of sugary rice. J. Med. Food 2012, 15, 399-405. [CrossRef] [PubMed]

39. Wang, Y.; Hamburger, M.; Gueho, J.; Hostettmann, K. Cyclohexanecarboxylic-acid derivatives from Psiadia trinervia. Helv. Chim. Acta 1992, 75, 269-275. [CrossRef]

40. Timmers, M.; Urban, S. On-line (HPLC-NMR) and off-line phytochemical profiling of the australian plant, Lasiopetalum macrophyllum. Nat. Prod. Commun. 2012, 7, 551-560. [PubMed]

41. Jou, S.J.; Chen, C.H.; Guh, J.H.; Lee, C.N.; Lee, S.S. Flavonol glycosides and cytotoxic triterpenoids from Alphitonia philippinensis. J. Chin. Chem. Soc. 2004, 51, 827-834. [CrossRef]

42. Yan, J.; Zhang, G.; Pan, J.; Wang, Y. $\alpha$-Glucosidase inhibition by luteolin: Kinetics, interaction and molecular docking. Int. J. Biol. Macromol. 2014, 64, 213-223. [CrossRef] [PubMed]

43. Yin, Z.; Zhang, W.; Feng, F.; Zhang, Y.; Kang, W. $\alpha$-Glucosidase inhibitors isolated from medicinal plants. Food Sci. Hum. Wellness 2014, 3, 136-174. [CrossRef]

44. Enomoto, S.; Okada, Y.; Guvenc, A.; Erdurak, C.S.; Coskun, M.; Okuyama, T. Inhibitory effect of traditional Turkish folk medicines on aldose reductase (AR) and hematological activity, and on AR inhibitory activity of quercetin-3-O-methyl ether isolated from Cistus laurifolius L. Biol. Pharm. Bull. 2004, 27, 1140-1143. [CrossRef] [PubMed]

45. Han, J.M.; Kim, M.H.; Choi, Y.Y.; Lee, H.; Hong, J.; Yang, W.M. Effects of Lonicera japonica Thunb. on type 2 diabetes via PPAR- $\gamma$ activation in rats. Phytother. Res. 2015, 29, 1616-1621. [CrossRef] [PubMed]

46. Peng, L.Y.; Mei, S.X.; Jiang, B.; Zhou, H.; Sun, H.D. Constituents from Lonicera japonica. Fitoterapia 2000, 71, 713-715. [CrossRef]

47. Borah, S.; Das, A.K.; Saikia, D.; Borah, J. A note on the use of ethnomedicine in treatment of diabetes by Mishing communities in Assam, India. Ethnobot. Leaflets 2009, 13, 1348-1352.

Sample Availability: Not available.

(C) 2016 by the authors; licensee MDPI, Basel, Switzerland. This article is an open access article distributed under the terms and conditions of the Creative Commons Attribution (CC-BY) license (http:/ / creativecommons.org/licenses/by/4.0/). 